Tattva, Vol. 1, No. 2, July-December 2009, pp. 45-56 ISSN 0975-332X | https://doi.org/10.12726/tjp.2.4

\title{
Tattua
}

JOURNAL OF PHILOSOPHY

\section{TESTING WHITEHEAD'S THEORY OF LEARNING EMPIRICALLY: A REPORT FROM A PILOT STUDY}

\author{
Franz Riffert, Josef Kriegseisen*, Tina Hascher, \\ Gerda Hagenaver \\ University of Salzburg, Department of Education \\ * University of Applied Education, Salzburg, Austria
}

\section{Introduction}

Alfred North Whitehead is well known for his cooperation with Bertrand Russell on the three volumes of the Principia Mathematica (1910, 1912, 1913). But Whitehead also was a philosopher who developed a metaphysical system which was intended to integrate the basic scientific research results of his time (Cobb \& Griffin 1977; Riffert \& Cobb 2003). In addition, he also dealt with educational topics; most of his papers on education are collected in his book The Aims of Education and Other Essays (1929/1967). His thoughts on education were taken up by a number of scholars (for instance Allan, 2004 \& 2005; Allan \& Evans, 2006; Birch, 1988; Brumbaugh, 1982 \& 2007; Burnett, 1957 \& 1961 \&; Evans, 1998; Gershman, 1988 \& Gershman \& Oliver, 1987; Hendley, 1976 \& 1986; McGuire, 1976; Riffert, 2005a, Scarfe, 2005; Woodhouse, 1993, to name but a few). The main emphasis was laid on the relationship between Whitehead's philosophic thought and his 
educational ideas. Implementing his theory of learning and instruction in schools and, even further, testing its efficiency, however, was only rarely discussed and never undertaken. This paper reports from a pilot study which aimed af taking first steps in that direction.

Whitehead was convinced that the formal education of his days was based on assumptions of a "false psychology" $(1929 / 1967,17)$. One of the most crucial assumptions which proved to be so harmful for education is the idea that students progress in a uniform way devoid of any growth spurts and delays. He was convinced that this assumption violates the basic characteristic of the learning process. According to Whitehead the world is constituted by pulsating processes; and the learning processes themselves are pulsating cyclic processes too.

Having missed this crucial point, educational scientists and learning psychologists have failed from the start when developing their theories of learning and instruction. One of the devastating results of implementing such erroneous concepts to schools according to Whitehead is the creation of "inert ideas" (Whitehead, 1929/1967, 2) in the learner.

If this misconception of uniform continuous learning processes is combined with an external concept of standardized testing, which pays no attention to the pupils individuality and to the situation specific challenges, strengths and weaknesses of each single school, then cramming to the test is the likely outcome; therefore after nine or even more years of schooling too often the process of education has led to a total failure. "Education with inert ideas is not only useless: it is above all things, harmful - Corruptio optimi, pessima." (Whitehead, 1929/1967, 2) Today, however, the situation has not changed much. For instance, Vijay Gupta (2000) from the Department of Aerospace Engineering at the Indian Institute of Technology, Kanpur, summarizes the unwelcome consequences of the Indian JEE (Joint Entrance Examination) to the six Indian Instifutes of Technology in the following way: "[T]he practice of drilling has affected the general attitude of students towards the education process. It is reflected in their performance, in the narrowness of their vision and in their technological career achievements. Gone is the love for learning and the curiosity. Our students wait in the lectures for the bottom line, the formulae they can plug into or the recipe they can follow for the examination problem. Since the brighter among the school-going students are interested in preparing for the JEE, the entire school education stands adversely affected. The students now spend lesser and lesser time in exploring what is not directly relevant for JEE. The Cognition and Technology Group at Vanderbilt (USA) $(1992,293)$ explicitly refers to Whitehead when describing the fatal consequences of our current educational system: "Findings from a number of studies suggest that knowledge that is not acquired and used generatively tends to become what Whitehead (1929) called 'inert knowledge' - 
knowledge that is not used spontaneously even though it is relevant". And Nickerson $(1988,5)$ summarizes his analysis of US-wide testing results by maintaining: "In the aggregate, the findings from these studies force the conclusion that it is possible to finish 12 or 13 years of education in the United States without developing much competence as a thinker."

Whitehead did not simply confine himself to criticising the dominating educational practice but developed an alternative theory of learning and instruction which is based on and inspired by his philosophic ideas.

\section{Whitehead's Cyclic Theory of Learning}

Whitehead's theory of learning is based on the idea of cyclic rhythm. This concept of periodic rhythm is not only important in the field of education but also for human life as such and even in all domains of reality. "There are minor eddies, each in itself a threefold cycle, running its course in each day, in each week, and in each term" $(1929 / 1967,38)$ and in each year and longer time periods (seasons, years) (Whitehead, 1929/1967, $21 \& 1919,197)$. In White-head's metaphysics actual entities (i.e. micro-processes) account for this pulsaling, cyclic rhythm. Actuol entities, the basic building blocks of reality, grow out of preceding actual entities and when reaching their determination they vanish by taking over the role of a preceding actual entity for further concrescences of actual entities. Then new cyclic pulsations start and so form the dynamic, complex and interwoven grid of the universe. The phased process of an actual entity starts with passive and vague reception of what is there and passes into an actively constructed definiteness which in return fuels newly emerging actual occasions. Such pulsaling micro-processes stretch throughout the whole universe but become especially obvious in living organisms. Within this frame of thought it is only a natural step to the formulation of cyclic and rhythmic learning processes at the human level.

Each single process of learning consists of three phases which Whitehead termed 'romance', 'precision', and 'generalization'; he also used the terms "threefold cycle of freedom, discipline, and freedom" $(1929 / 1967,31)$ for these three phases of a full learning cycle.

At the slage of romance the student is in a process of discovery; for the first time s/ he encounters a new situation. "The stage of romance is the stage of first apprehension." $(1967,17)$ As long as the new stimuli are at least faintly conceived as relevant by the student it will evoke interest and some sort of emotional arousal in the learner. A new situation is relevant to a student if $s /$ he can relate him/herself to the new situation i.e. the sifuation should not be completely new, different or 
foreign to him/her but that it should be possible for the student to discern possible connections to his/her earlier experiences. "Education must essentially be a setting in order of a ferment already stirring in the mind: you cannot educate mind in vacuo." $(1967,18)$ However, at this stage the relations and connections between the new stimuli and between them and the student still remain vague, only half disclosed. Such vague apprehensions hold "within itself unexplored connexions with possibilities half-disclosed by glimpses and half concealed by the wealth of material." $(1929 / 1967,17)$ Half disclosed as they may be, they certainly are emotion laden. "Romantic emotion is essentially the excitement consequent on the transition from bare facts to the first realization of the imporf of their unexplored relationships." $(1929 / 1967,18)$

This first phase of a learning cycle is of great importance, for it triggers in the learner excitement and emotional arousal towards possibilities which flash up in the learner. In this phase "[ $[$ ]he students should see for themselves, and test for themselves, with only fragmen-tary precision of thought." (Whitehead, 1929/ $1967,23)$ Without this intrinsic arousal hardly any interest for and curiosity in exploring the situation in any further detail would be shown on the side of the student. This descriptive aspect of learning has implications for a pre-scriptive theory of feaching and instruction: intrinsic motivation cannof develop without giving enough space and time for the stage of romance. Traditional education has violated this central postulate of a process theory of teaching because of its linear piecemeal account of learning.

The second stage is termed the slage of precision. Here the student investigates and elaborates in detail the exact relationships of the new stimulus patterns among themselves, in relation to other, already well known stimulus patterns and to the learner her/himself. "In this stage, width of relationship is subordinated to exactness of formulation. It is the stage of grammar, the grammar of language and the grammar of science." $(1929 / 1967,18)$ Time and again Whitehead draws our aftention to the fact that "a stage of precision is barren without a previous stage of romance: unless there are facts which have already been vaguely apprehended in their broad generality, the previous analysis is an analysis of nothing. It is simply a series of meaningless statements about bare facts, produced artificially and without any further relevance." $(1929 / 1967,18)$ It is of utmost importance that the phase of precision always follows but never precedes a phase of free roaming romance; if this rule is violated - as in fact it is the case in traditional linear education - inert knowledge is the very likely result. "Thus precision will always illustrate subject matter already apprehended and crying out for drastic treatment." $(1929 / 1967,25)$ Whitehead accuses traditional education with 
its lack of emphasis on the romantic phase of producing such inert ideas "that are merely received into the mind without being utilized, or tested, or thrown into fresh combinations." $(1929 / 1967,1)$

The stage of precision adds definiteness and exactness to the contents grasped at the stage of romance. It consists "of analyzing the facts, bit by bit." (1929/1967, 18) The broadly but vaguely apprehended and only half disclosed contents of the romantic phase are specified in detail and systemalized. Such detailed elaborations require discipline. In its ideal form such discipline is self-discipline motivated by the lures introduced by the stage of romance.

There are many different sources according to Whitehead why traditional teaching failed; one, as we have already seen, is that the teaching process tacilly was modeled after a linear concept of development. Another, not less disastrous mistake of traditional education, consists in the production of inert knowledge because the phase of precision or discipline is over-emphasized and the stage of romance is neglected. But "[w]ithout the adventures of romance, at the best you get inert knowledge without initiative, and at worst you get contempt of ideas - without knowledge." $(1929 / 1967,33)$

However, there are ditches on both sides of the road. And so Whitehead argued not to over-emphasize the stage of romance either. He repeatedly stresses the fact that romance has to be counter-balanced by what he called the stage of 'precision' or 'discipline'. And in this line of argumentation Whitehead draws our attention to the fact that there "are right ways and wrong ways, and definite truths to be known." $(1929 / 1967,34)$ Therefore the stage of disciplined precision is important as well. There cannot be any doubt that "a certain pointing out of important facts, and of simplifying ideas, and of usual names really strengthens the nofural impetus of the pupil." $(1929 / 1967,33)$

The final and third stage of a learning cycle is the stage of generalization. It marks at the same time the culmination of the learning cycle in question and the stort of a new cycle. So Whitehead can say that we arrive here at the "return fo romanticism" $(1929 / 1967,19)$. The newly acquired, detailed and interrelated definitive knowledge is applied to new situations i.e. to new challenging stimulus patterns; in doing this, again new exciting perspectives and fascinating half-disclosed insights are gained: a new cycle of learning is about to start.

Whitehead sums up the general character of a full learning cycle with its three phases in the following words: "There is the general apprehension of some topic in its vague possibilities, the mastery of the relevant defails; and finally the putting of the whole subject together in the light of the relevant knowledge." $(1929 / 1967,38)$ 
Unlike John Dewey, who had founded the so-called laboratory school in order to imple-ment his educational ideas in the field of practice (see for instance: Tanner, 1997), Whitehead never applied his theory directly to school reality. The more important it is to see whether the efficiency of his learning theory can gain empirical support.

\section{First Steps towards Testing Whitehead's Theory of Learning Empirically}

In order to test Whitehead's cyclic learning theory a pilot study was designed. The hypotheses, the design and instruments (3.1), as well as some results (3.2) will be presented in this section. It has to be noted however that, despite the fact that we did test some hypotheses, this study primarily was aiming at gaining insight into the quality of the research design the instruments implemented for measuring the effects in order improve future studies, the learning cycles applied and the teaching process.

\subsection{Questions, Hypotheses, Design, and Instruments}

Answers to the following questions were aimed at: (i) Does the learning cycle approach lead to improvement in cognitive development (as compared to traditional teaching)? (ii) Does the learning cycle approach improve the students' inferest in science (as compared to traditional teaching)?

The hypotheses are formulated respectively: $\mathrm{Hl}$ : The learning cycle approach significantly $(p<.05)$ improves cognitive development. H2: The learning cycle approach significantly $(p<.05)$ increases the students' interest in science.

In the school year 2007/08 the learning cycle approach was implemented at an Austrian secondary school in one science class (physics and chemistry; 258 thgrade-students, 13 girls and 12 boys; treatment group) while another science class (24 8th-grade-studnets, 11 girls and 13 boys, control group) was taught in a traditional, linear, non cyclic way. The treatment lasted for a full school year and consisted altogether of six learning cycles; three chemical cycles in the winter semester: 1. water, 2. air, 3. acids and bases; three cycles in the field of physics during the summer semester: 1. electrical devices, 2 . light and colours, 3. radioactivity.

Given the fact that due to obvious ethical restrictions no random samples could be gathered, before starting the pilot study, intelligence of all students was measured using the German version (Weiß, 1987) of the Culture Fair Intelligence Test-Scale 2 (CFT 20, Cattell \& Cattell 1960). 
For measuring the dependent variable, i.e., the cognitive development according to Piaget's stage theory, Science Reasoning Tasks (SRT) (Wylam \& Shayer, 1980) were used before ( 2 tasks for the pre-tests within an interval of 14 days: SRT II: volumes and heaviness \& SRT IV: equilibrium and balance) and after the end of intervention ( 2 (different) tasks for the post-tests with an interval of 7 days; SRT VII: flexible rods \& SRT I: spatial relationships). The SRT were developed on the basis of Piaget's clinical intenviews and their reliability and validity were tested in a large survey study in Great Britain (Shayer \& Wylam, 1978). They cover the cognitive developmental range from pre-operational to formal operational sfage (including sub-stages) (Shayer \& Adey, 1981; see Table 1).

\begin{tabular}{|c|}
\hline Cognitive Levels \\
\hline $1 \mathrm{~B}$ pre-operational \\
\hline $2 \mathrm{~A}$ early concrete \\
\hline $2 \mathrm{~A} 2 \mathrm{~B}$ middle concrete \\
\hline $2 \mathrm{~B}$ mature-concrete \\
\hline $2 \mathrm{~B}^{*}$ concrete-generalized \\
\hline $3 \mathrm{~A}$ early-formal \\
\hline $3 \mathrm{~A} 3 \mathrm{~B}$ mature-formal \\
\hline
\end{tabular}

Table 1: Cognitive (sub) stages as measured by SRT

In addition interest in science (physics and chemistry) was measured. For this purpose before and immediately after the infervention a selection (scale concerning subject interest, 20 items) from measurement tool for students' interest conceptions concerning physics and chemistry developed at the IPN (Institut für die Pädagogik der Naturwissenschaften) at Kiel University by Hoffmann, Häußler, and Lehrke (1998) were used.

\subsection{Results}

The measurement of intelligence showed that there was no significant difference between the two groups (mean value treatment group: $\mathrm{M}_{\mathrm{lQ}}=100.00, \mathrm{SD}=12,92$; control group: $M_{1 Q}=99.72, S D=13,16$ ); so the two classes were comparable concerning this central characteristic.

Concerning the SRT the first post-test task (SRT I) had to be skipped since it only measured cognitive development up to level $2 \mathrm{~B}$ producing a ceiling effect; so only task (SRT VII) remained for calculations. In a first step the group differences in the 
pre-tests 1 and 2 (arithmetic mean value of both tests) and post-tes 2 were calculated: pre-test 1 shows a highly significant difference $(t(40)=-2,714, p<.010)$ between the two groups (classes). Therefore the calculated significant differ-ence in the post-test $(t(40)=-4,709, p=.000)$ cannot attributed to the freatment (learning cyc-les).

A closer inspection, taking into account each single pre-test, however, comes up with the following results: In pre-test 1, SRT II: volumes and heaviness, no significant difference between the two groups was measured with a T-test for independent samples: $t(36)=-1,151, p=.257$. Pre-test 2 , SRT IV: equivalence and balance, showed a significant difference between the two groups (T-test for independent samples); $t(36)=-3,234, p=.003$. Post-test 2 , SRT VII: flexible rods, showed a high significant difference between the two groups (T-test for independent samples) $f(36)=-3,710, p=.001$. Since pre-test 2 (SRT IV) showed a significant difference between the two groups (classes) a T-test for paired samples was performed only for pre-test I (SRT II) which had shown no significant difference between the two groups, and post-test 2 (SRT VII).

The treatment group shows a highly significant mean value difference between times 11 (pre-test) and 12 (post-test): $t(22)=-2,816, p=.010$. This means that for pre-test] (SRT II) and post-test 2 (SRT VII) the treatment accounts for the effect measured. Turning to the measurement of subject interest (physics and chemistry) the following results were obtained: „SS]tudents in the Experimental group did not differ significantly from students in the Control group in both pre- and post-tests of subject interest (Pretest: $t(43)=1.82, p=0.076$; Post-test: $1(41)=0.49, p=$ $0.63)$. Because of these insignificant results, no further analyses based on statistical tests have been made. However, an inspection of mean scores indicates that subjects' interest has been stable in the Experimental group (from pre- to post-test: 64.00 ys. 65.32), but has been reduced in the Control group (58.46 vs. 67.05) (a larger mean score indicates lower interest)." (Astleitner, Kriegseisen \& Riffert, 2009)

\section{Interpretation and Future Perspectives}

The results concerning the impact of the learning cycle approach on the cognitive development of the students indicate that there is a positive treatment effect, although the results are not decisive: the results of pre-test 1 (SRT II) and post-test 2 (SRT VII) confirm the hypotheses while the results of pre-test2 (SRTIV) and post-test 2 cannot be interpreted in this direction. There may be several reasons which - ex post- may account for this result: First, the treatment duration of one school year might not have been long enough. Second, the treatment validity may not be (fully) given; this is indicated by talks with the teacher and unsystematic video recordings. In 
particular it seems that the third learning cycle phase, generalization does not seem to have been implemented in an optimal way. This is further supported by the results concerning emotions in the single phases, in particular to the unexpected results concerning the phase of generalization: measurement showed that in accordance with expectation during the romance phase the sfudents did report a maximum of positive and a minimum of negative emotions (as compared to the other two phases: precision and generalization); concerning the generalization phase the students did report a minimum of positive and a maximum of negative emotions and this despite the fact that according to Whitehead in the generalization phase a return to romance takes (should take) place (see: Hascher, Hagenauer, Kriegseisen \& Riffert, 2009). In order to be able to test treatment volidity in future studies an observation tool has been developed by one of the authors (Riffert, 2009). Third, the durations of lessons - in our case 100 minutes (i.e. two traditional lessons of 50 minutes each) interrupt the learning processes artificially, especially the romance and generalization phase; this may reduce the impact of this learning approach on the students. Finally, one can speculate if the students were well-prepared for learning in a learning cycle manner. Especially in the romance and the generalization phase the students are challenged as active learners, exploring, investigating and testing their own actively generated hypotheses. The students of the treatment class never before had to learn in this ambitious way and according to the teacher's report some of them seemed to be unable to cope with this demanding situation. At present all these explanations are but speculations and have to be tested in future studies.

Turning to the impact on students' interest in science (physics and chemistry) it has to be stated that the impact of the treatment is less clear: although the mean scores show that the subjects' interest remained stable in the treatment group - which runs counter to the usual research results in this domain - while in the control group the interest in science declines, both groups do not differ significantly. Again one can speculate about the reasons for this result: the demanding learning situation may have produced in the students the conviction that these fields of study are very difficult, maybe too difficult for them which, as a consequence, may have lead to a decline of interest. Here too future sfudies will have to throw light on this topic.

In general it has to be stated that the sample was too small to infer generalizable consequences from the results, which, as stated above, was not the primary intention of this pilot study anyway. The major intention was to get first impressions concerning the quality of the measurement instruments, the quality of the developed learning cycles, and the teaching activities. In all these respects the study has lead to important insights. 
Future studies can build on the results presented in this paper. Such studies will have to be planned for more classes in order to receive results which are, ot least to some extent, generalizable. Also treatment validity will be tested by use of the developed observation tool. Further it will be important a) teach the learning cycles longer than just one school year and b) to vary the duration of the single phases systematically in order to test its impact on the outcome.

Another challenging task would be to transfer the learning cycle approach from science classes to other subjects such as history and geography or psychology and philosophy. Also the learning cycle approach could be elaborated by explicilly including some additional aspects such as for instance systematic and differentiated investigations of the role of emotions during the single phases of a learning cycle. Of course also implementing the learning cycle approach in different cultures with its different learning and school traditions would allow for exciting cross-cultural comparisons.

Ending this paper a refurn to Whitehead is in order to avoid losing a realistic and humble outlook. He drew attention to the fact that successful teaching "depends on a delicate adjustment of many variable factors. The reason is that we are dealing with human minds, and not with dead matter." (Whitehead, 1929/ 1967 , 5) And based on this insight that the learning process depends on a complex web of various causes Whitehead warned not to underestimate the challenge for the teachers when s/he tries to organize such processes in an optimal way: "To speak the truth, except in the rare case of genius in the teacher, I do not think that it is possible to take a whole class very far along the road of precision without some dulling of the interest. It is the unfortunate dilemmo that initiative and training are both necessary, and that training is apt to kill initiative. But this admission is not to condone a brutal ignorance of methods of mitigating this untoward fact. [...] we are discussing how to reduce the evil to its smallest dimension." (Whitehead, 1929/1967, 35f)

The pilot study presented in this paper is a humble attempt to take first steps towards testing the efficiency of Whitehead's cyclic learning approach which aims at improving the students' interest and competences in learning and thereby contribute to the reduction of the 'evil' of traditional teaching. Important information has been gathered in this study concerning the design, the treatment (duration of lessons/single cycle phases, teaching activities, quality of learning cycles), application of the measurement tools (especially the SRT); also an observation tool was developed to test treatment validity. So, important preparatory steps have been made for a large scale testing Whitehead's cyclic learning theory. 


\section{Reference:}

01. Allan, G., Higher Educotion in the Making: Pragmatism, Whitehead, and the Canon (New York: SUNY Press, 2004)

02. Allan, G., "Solomon's Dream and Whitehead's Rhythm of Education." Process Sludies, 34/ 2 (2005), 224-239.

03. Allan, G. and Evans, M.D. (Eds.). A Different Three Rs for Education: Reason, Rela-tionality, Rhythm (Amsterdam and New York: Rodopi, 2006).

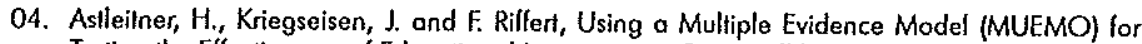
Tesling the Effecliveness of Educational interventions. Paper will be presented al the European Conlerence for Educotional Research in Vienna, September 28-30, 2009; the paper will be submitted to EERA-publication-projects on educalional effectiveness and/or evidence-based quality ossurance.

05. Birch, C., "Whitehead and Science Education." Educotional Philosophy and Theory, 20/2 (1988), 33-41.

06. Brumbaugh, R.S., Whitehead, Process Philosophy, and Education (Albany, NY: Sunny Press, 1982).

07. Brumbaugh, R.S., "Whitehead as a Philosopher of Educalion: Abstroclion, Action, Solisfaction." Educotional Theory, 15/4 (2007), 277-281.

08. Burnelt, J., "Whitehead's Concept of Creativity and Some of its Educational Implications." Harvard Educollonal Review, 27 (1957), 220-34.

09. Burnett, J., "A. N. Whitehead on the Aims of Schooling." Educational Theory, 4/4 (1961), 269-278.

10. Cattell, R.B. and A. K. S. Cattell, Handbook for the Individual or Group Culture Faire Intelligence Test (Champagne, lll.: IPAT, 1960).

11. Cobb, J. and Grilfin, D.R. (Eds.), Mind in Nafure: Essays on the Interface of Science and Philosophy (Washington: University Press of America, 1977).

12. "Cognifion and Technology Group af Vonderbilt, The Jaspers Series as an Example of Anchored Instruction: Theory, Programme Description and Assessment Dato." Educalional Psychologist, 27 (1992), 291-315.

13. Evans, M.D., Whitehead and Philosophy of Education. The Seamless Coat of Learning (Amslerdam: Rodopi, 1998).

14. Gershmon, K., "To and Fro: Education for the Art of Life." Process Studies, $17 / 4$ (1988), 215-226.

15. Gershman, K. \& Oliver, D. W., "Towords A Process Pedagogy." Process Siudies 16/3 (1987), 191-197.

16. Gupta, V., Joinf Entrance Examination: A Critique. Directions, 3/4, 2000. [online journal] available ol: htto://www.iilk.ac.in/infocell/Archive/dirjuly3/cover_story.html [access: April 20,2009 ]

17. Hascher, T., Hagenauer, G., Kriegseisen, J. and Riffert, R., Lernzirkel im Physik- und Chemieunferricht in der Sekundarstufe 1. [Learning cycles in Physics and Chemistry Classes in Secondary Schooll Erziehung und Unterricht, poper accepted, 2009.

18. Hendley, B., "A Whiteheadion Model for Teaching Introduclory Philosophy." Metaphilosophy, 7 (1976), 307-315. 
19. B. Hendley, Dewey, Russell, Whitehead: Philosophers as Educators (Carbondale, Ill.: Southern Illinois University Press, 1986).

20. Hoffmann, L., Häußler, P. and Lehrke, M., Die IPN-Interessensstudie Physik [The IPN-InterestStudy in Physics). (Institut für die Pädagogik der Nolurvissenschaften an der Universitäł Kiel, 1998).

21. McGuire, E.J., "Alfred North Whitehead and the Teaching of Science in the Secondary School." School Science and Mathemalics, 5 (1976), 425-431.

22. Nickerson, R.S., "On Improving Thinking through Instruction." Review of Research in Education, 15 (1988), 3-57.

23. Riffert, F., "Process Philosophy and Constructivist Educotion: Some Basic Similarities." Salzburger Beiträge zur Erziehungswissenchaft, 2/2 (1999), 68.77.

24. Riffert, R. (Ed.), Affed North Whitehead on Learning and Education: Theory and Application (Newcostle: Cambridge Scholor Press, 2005a).

25. Riffert, F., "Via Negativa: Whitehead's Crilique of Traditional Concepls of Learning and Instruction." In F. Riffert (Ed.). Afred North Whitehead on Learning and Education: Theory and Application. Newcastle: Cambridge Scholar Press, 2005b, 7-14.

26. Riffert, F., Lernzyklen und ihre Beobachtung im Unterrichl - Zwischenbericht zur Entwicklung eines Beobachtungsinstruments. Salzburger Beitröge zur Erziehungswissen-schaft, 12/1(2009), 67-99.

27. Riffert, F and Cobb, John B., "Reconnecting Science and Metaphysics: General Considerations and Pioneer Works on Process Psychology." In F. Riffert \& M. Weber (2003). Searching for New Contrasts. Whiteheadian Contributions to Contemporary Challenges in Neurophysiology, Psychology, Psychotherapy, and the Philosophy of Mind. New York: Lang, $2003,19.35$.

28. Scarte, A., "Selectivity in Learning: A Theme in the Application of Whitehead's Theory of Prehensions to Educolion." Inferchange, 36/1-2 (2005), 9-22.

29. Shayer, M. and Adey, P.S., Towords a Science of Science Teaching (London: Meinemann, 1981).

30. Shayer, M. and Wylam, P.S., "The Distribution of Piogetian Stages of Thinking in British Middle and Secondary School Children: II - 14- to 16.Yeor Olds and Sex Differentials." British Journal of Educational Psychology, 48 (1978), 62-70.

31. Tanner, L.N., Dewey's Laboratory School: A Lesson for Today (New York: Teacher College Press, 1997).

32. Weiß, R.H., Grundinfelligenzfest Skola 2 CFT 20 (Hogrefe: Göttingen, 1987).

33. Whitehead, A.N., Principia Mathematica (Cambridge: Combridge University Press, 1910, 1912, 1913).

34. Whitehead, A.N., An Enquiry Concerning the Principles of Natural Knowledge (Cambridge: Cambridge Universily Press, 1919).

35. Whitehead, A.N., The Aims of Education and Other Essays (New York: Free Press, 1929/1967).

36. Woodhouse, H., "Russell and Whitehead on the Process of Growth in Education." The Journal of Bertrand Russell Archives. New Series, 12/2 (1993), 135-59.

37. Wylam, H. and Shayer, M., CMCS Science Reasoning Tasks: General Guide. Windsor: NFER Publishing, 1980). 